\title{
PEA CRAB DISTRIBUTION AND ITS MORPHOLOGICAL CHARACTERISTICS STUDIED IN BIVALVES FROM SETIU WETLANDS, TERENGGANU
}

\author{
NOR OMAIMA HARUN ${ }^{1 *}$, NIK NUR SHAHIERA CHE ABDULLAH ${ }^{1}$ and \\ MHD IKHWANUDDIN ABDULLAH ${ }^{2}$ \\ ${ }^{1}$ School of Science and Marine Environment, Universiti Malaysia Terengganu, \\ 21030 Kuala Nerus, Terengganu, Malaysia \\ ${ }^{2}$ Institute of Tropical Aquaculture, Universiti Malaysia Terengganu, \\ 21030 Kuala Nerus, Terengganu, Malaysia \\ *E-mail: omaima@umt.edu.my
}

Accepted 17 November 2020, Published online 25 December 2020

\begin{abstract}
Pea crab is a small crustacean known as kleptoparasite and belongs to the family Pinnotheridae, inhabit bivalves, gastropods, and other species. Nonetheless, pea crab is one of the unfamiliar species to the Malaysia citizen and the information is limited. This study aimed to determine the distribution of pea crab from four bivalves species (mud clam, oyster, hard clam and cockle) in Setiu Wetlands, Terengganu. Sampling was conducted twice, in October 2018 and February 2019, in which mud clam, oyster, cockle and hard clam were collected. In this study, the distribution of pea crab was observed by collecting randomly fifty samples of each bivalve at four sites and checked for any presence of pea crab. The size shell length of mud clams measured was 40 to $75 \mathrm{~mm}$, oysters were 30 to $80 \mathrm{~mm}$, marine clams and cockles were 20 to $40 \mathrm{~mm}$. Pea crab presence was analysed and identified for the genus identification based on the microscopic and macroscopic methods. The result showed that, pea crab only present in the mud clam but none in other bivalves. Fifteen pea crabs were isolated from the first sampling (mean=0.3) with 11 females, whilst 13 pea crabs from the second sampling (mean=0.26) with 10 femalesidentified. The size of the pea crab measured was between $10 \mathrm{~mm}$ to $15 \mathrm{~mm}$ and belongs to the genus of Arcotheres sp. However, there were other none pea crab species were found in the oyster. On the other hand, the correlation between the carapace width of pea crab and mud clam shell length were analysed using linear regression $\left(r^{2}=0.0699, p=0.341\right)$ from first sampling, while $\left(r^{2}=0.2885, p=0.058\right)$ from second sampling. The size range of mud clams without pea crab was 35 to 60 mm shell length.
\end{abstract}

Key words: Arcotheres sp., hard clam, pea crab, microscopic, macroscopic, clam shell

\section{INTRODUCTION}

Pea crab is a small crustacean in the family Pinnotheridae and mostly associated with other marine animals like bivalves, gastropods, and holothurians in the name as a symbiotic relationship either as a parasitic or commensalisms. The symbiotic relationship between pea crab and bivalve can cause serious impact on the economy in the aquaculture production (Trottier \& Jeffs et al., 2015). Bivalvia is the second-largest class and economically important in the phylum of Mollusca. Also, bivalves play an important role in feeding the world's population. As reported earlier, pea crab is

* To whom correspondence should be addressed. more attracted to bivalves such as oyster, mud clam, mussel, and cockle. The life cycle of pea crab started with a larval stage in which takes place in the open ocean and live within the host once reach adult stages for food, protection against predator and oxygen.

Also known as kleptoparasite because of its behaviour stealing food from their host when food supply is less, the presence of pea crab in which normally can be found in the mantle cavity of the carapace specifically the gill area can give effect and damaging the host's gills. As a result, the size of the hosts become smaller due to the nutrient intake by the pea crab and insufficient foods.

A report from Yahya et al. (2016), stated that the highest diversity of bivalves in the brackish 
subtidal area occurred at seagrass and estuary ecosystems bordered by mangrove forest which are a highly productive ecosystem. In this study, sampling was taken place in Setiu Wetlands, Terengganu. Setiu Wetlands consisted of several different habitats which are estuaries, sandflats, mudflats, mangrove forest, coastal brackish, lagoon, marshes, freshwater swamp forest, and lowland dry forest. Thus, this study is to investigate and determine pea crab distribution in bivalves based on morphological aspects from Setiu Wetlands.

\section{MATERIALS AND METHODS}

\section{Experimental design}

Setiu Wetlands located in the district of Setiu, Terengganu known as the largest natural wetlands in the East Coast region of Peninsular Malaysia. Setiu Wetlands consists of three river basins that converged and form a continuous lagoon $14 \mathrm{~km}$ long and includes several different habitats which are estuaries, sandflats, mudflats, mangroves forest, coastal brackish, lagoons, marshes, freshwater swamp forest, and lowland dry forest. The samplings were conducted twice in October 2018, during monsoon and February 2019, during the dry season.

\section{Samples collection}

Fifty individuals of oysters, mud clams, cockles, and hard clams were collected randomly by handpicking at four different sites. The mud clam was collected at a sandbar near to Pulau Semut; cockles and hard clam were collected at Kuala Lama and in front of the boardwalk, respectively. Whilst, the oyster was collected at the mangrove area. Each sample was placed into the specimen container bottle and brought back to the laboratory for further analysis.

\section{Isolation of pea crab}

Bivalves sample were opened carefully using scalpels and any presence of pea crab was recorded.

\section{Distribution and identification of pea crab}

Pea crab found was examined using the macroscopic method by observing their external morphology, followed by a further microscopic method using stereomicroscope (Olympus) for its detailed morphology.

\section{Morphometric measurement of bivalves}

The measurement of bivalves and pea crab were taken based on morphological characteristics such as length, width, and height by using a vernier calliper. The measurements were taken by referring to Figure 1.

\section{Data collection and statistical analysis}

The length-width relationship between host and pea crab were determined by using a linear regression line. The statistical tests (ANOVA) were done using Microsoft Excel and the mean number of pea crab was illustrated in a histogram.

\section{RESULTS}

A total number of pea crab isolated from fifty samples of each bivalve species during monsoon season was 15. Table 1 shows the total number of pea crab isolated from four species of bivalves. The pea crab only found in the mud clam with a mean number of 0.3 .

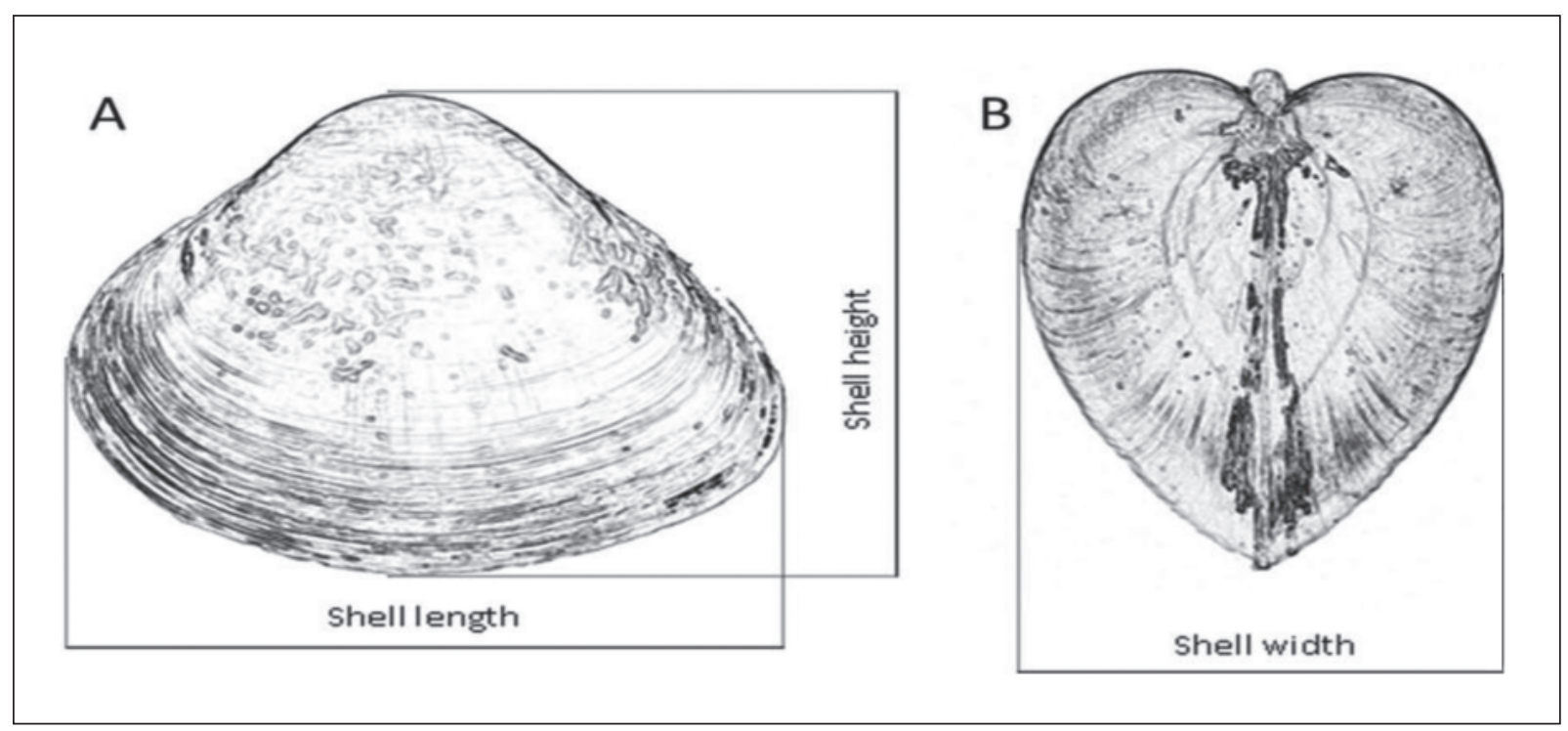

Fig. 1. Morphometric measurement of bivalves based on shell length, height and width (Turra et al., 2018). 
Table 1. The total number of pea crab isolated from each species of bivalves during monsoon season sampled in Setiu Wetlands, Terengganu

\begin{tabular}{lcccc}
\hline Bivalves species & $\begin{array}{c}\text { Total Number of } \\
\text { Bivalves sample }\end{array}$ & $\begin{array}{c}\text { Total Number of } \\
\text { Pea crab }\end{array}$ & $\begin{array}{c}\text { Total Number of } \\
\text { Other crab species }\end{array}$ & $\begin{array}{r}\text { Mean number of } \\
\text { existence crabs }\end{array}$ \\
\hline Marine clam & 50 & 0 & 0 & 0 \\
Mud clam & 50 & 15 & 0 & 0.3 \\
Cockle & 50 & 0 & 0 & 0 \\
Oyster & 50 & 0 & 0 & 0 \\
\hline
\end{tabular}

Table 2. The total number of pea crab isolated from each species of bivalves during dry season sampled in Setiu Wetlands, Terengganu

\begin{tabular}{lcccc}
\hline Bivalves species & $\begin{array}{c}\text { Total Number of } \\
\text { Bivalves sample }\end{array}$ & $\begin{array}{c}\text { Total Number of } \\
\text { Pea crab }\end{array}$ & $\begin{array}{c}\text { Total Number of } \\
\text { Other crab species }\end{array}$ & $\begin{array}{r}\text { Mean number of } \\
\text { existence crabs }\end{array}$ \\
\hline Marine clam & 50 & 0 & 0 & 0 \\
Mud clam & 50 & 13 & 0 & 0.26 \\
Cockle & 50 & 0 & 0 & 0 \\
Oyster & 50 & 10 & 0 & 0.2 \\
\hline
\end{tabular}

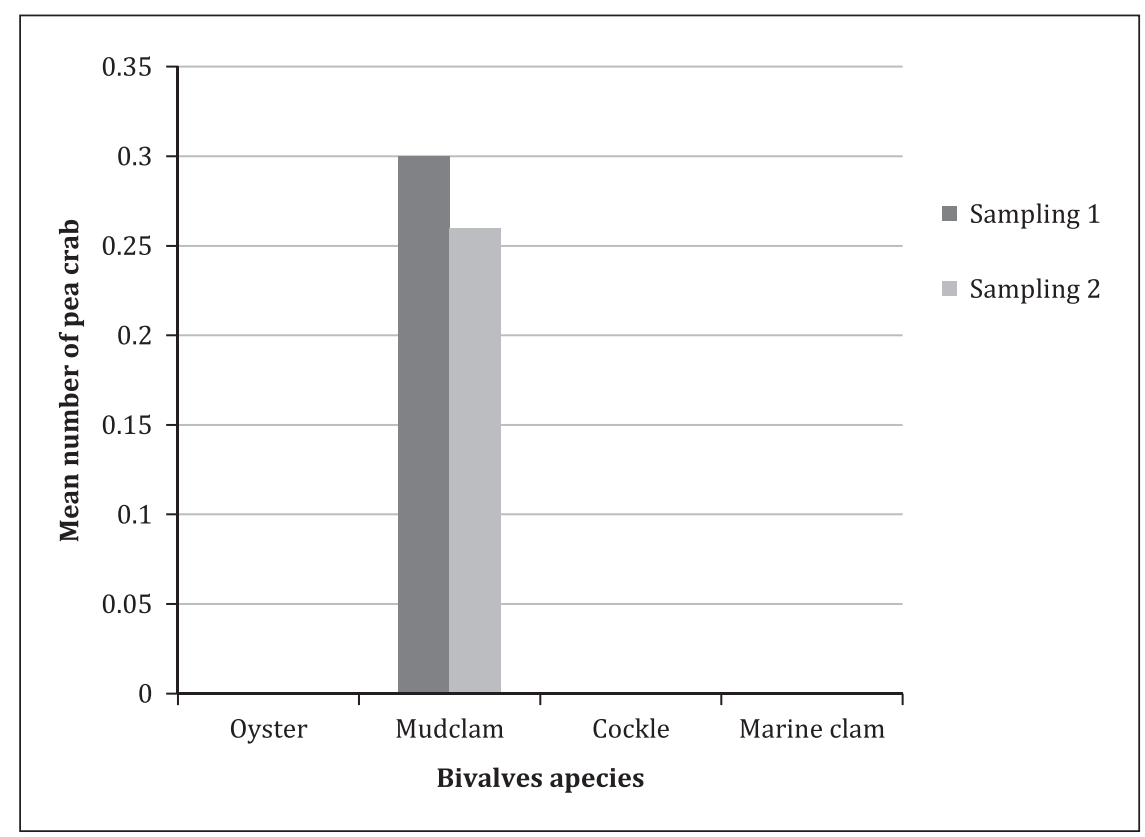

Fig. 2. Bar graph showing bivalves species against a mean number of pea crab.

In the dry season, a total number of pea crab isolated from fifty samples of each bivalve was 13 and 10 remain unidentified small crab isolated from the oyster. Table 2 shows the total number of pea crab isolated from four species of bivalves. The pea crab only isolated and recorded with a mean number of 0.26 and unidentified small crab for 0.2 .

Figure 2 shows the mean number of pea crab isolated and recorded in each bivalves species. However, pea crab only found in mud clam. Mean several pea crabs isolated from mud clam during monsoon season was 0.3 , whilst 0.26 during the dry season.

Pea crab length and width have also been measured and recorded as in Figures 3 and 4, respectively. Figures 3 and 4 shows the relationship between the pea crab carapace width and mud clam length $(\mathrm{mm})$ from both samplings time. The pea crab carapace width was measured from $10 \mathrm{~mm}$ to $15 \mathrm{~mm}$, whilst mud clam length was measured between 40 $\mathrm{mm}$ to $80 \mathrm{~mm}$. 
From both Figures 3 and 4, it is shown that smaller mud clam was not attracted by larger pea crab but in the larger host, small pea crab also can be found. Therefore, the maximum pea crab carapace width is dependent on the size of the host (Houghton et al., 1963). However, the linear regression relationship between pea crab carapace width and mud clam length were all not significant, although a regression of pea crab carapace width and the mud clam length showed a positive slope.

Figure 5 shows that location of pea crab found in the mantle cavity of mud clam during monsoon season (A) and dry season (B). There was only one pea crab found in each of the mud clams sampled.
Figure 6 shows the morphology of pea crab viewed from dorsal and ventral angles. Both $\mathrm{A}$ and $\mathrm{B}$ showed the dorsal view of pea crab carapace. The carapace of the pea crab was broader than long and having blunt. Figure $6(\mathrm{C})$ shows the structure of female pea crab abdomen that filled with eggs from a ventral view and bigger compare to male and Figure 6(D) shows male pea crab abdomen. Both pictures were from a ventral view. The external morphology of pea crab then was analysed by the macroscopic method and identified as the genus of Arcotheres (Ikhwanuddin et al., 2019).

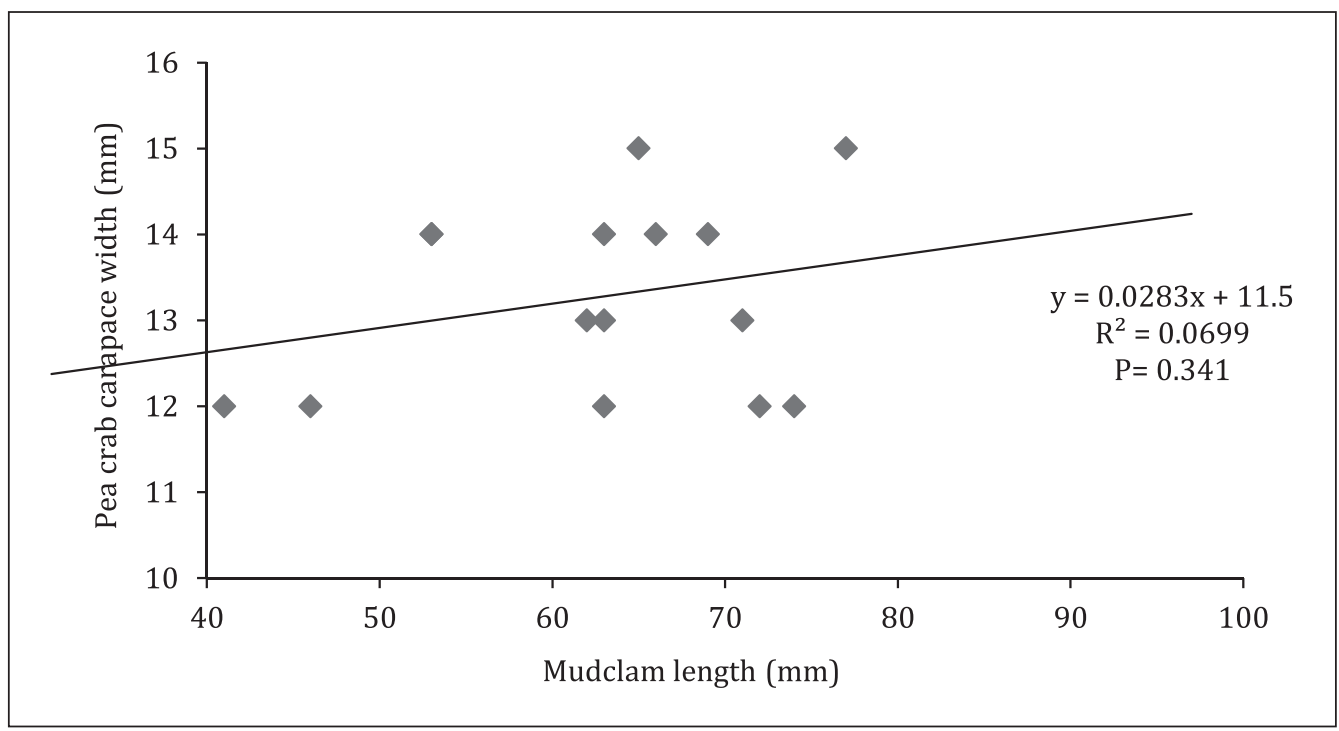

Fig. 3. Relationship between pea crab carapace width $(\mathrm{mm})$ and mud clam length $(\mathrm{mm})$. A significant trend indicates that larger mud clam host has larger pea crab sampled during monsoon season in Setiu Wetlands, Terengganu.

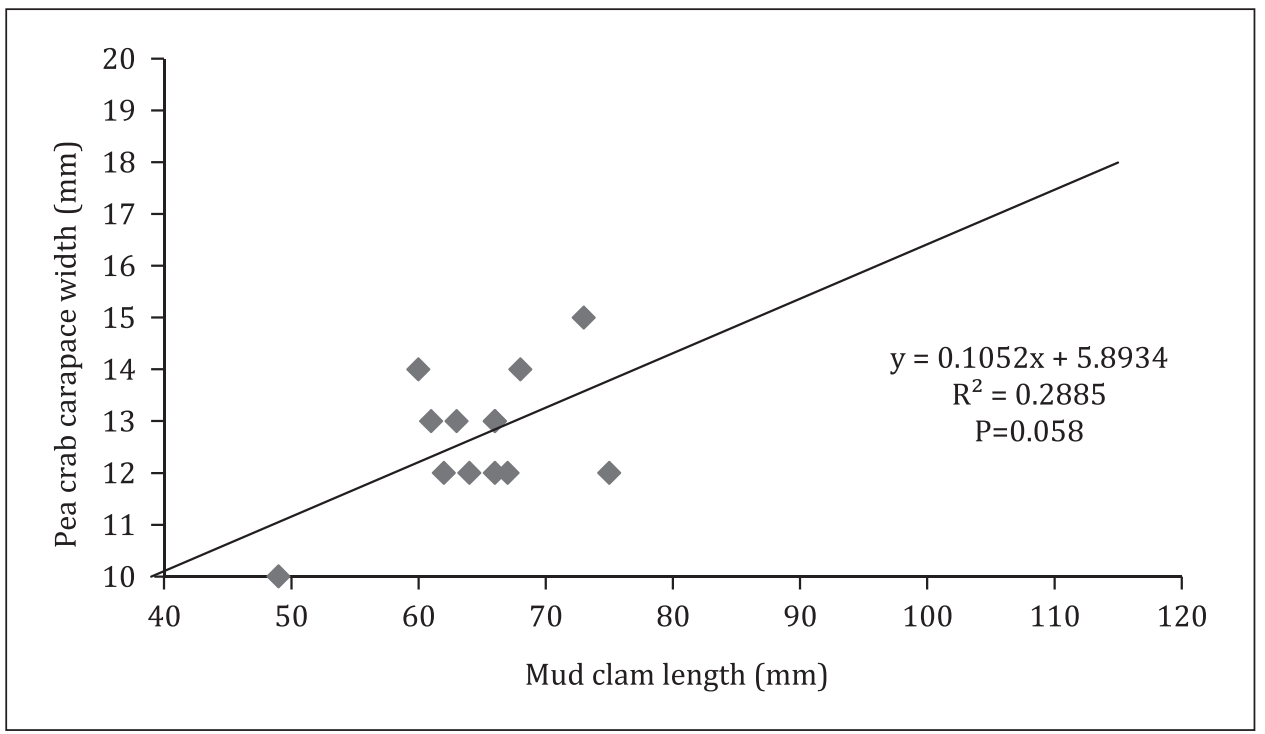

Fig. 4. Relationship between pea crab carapace width $(\mathrm{mm})$ and mud clam length $(\mathrm{mm})$ isolated during the dry season in Setiu Wetlands, Terengganu. 

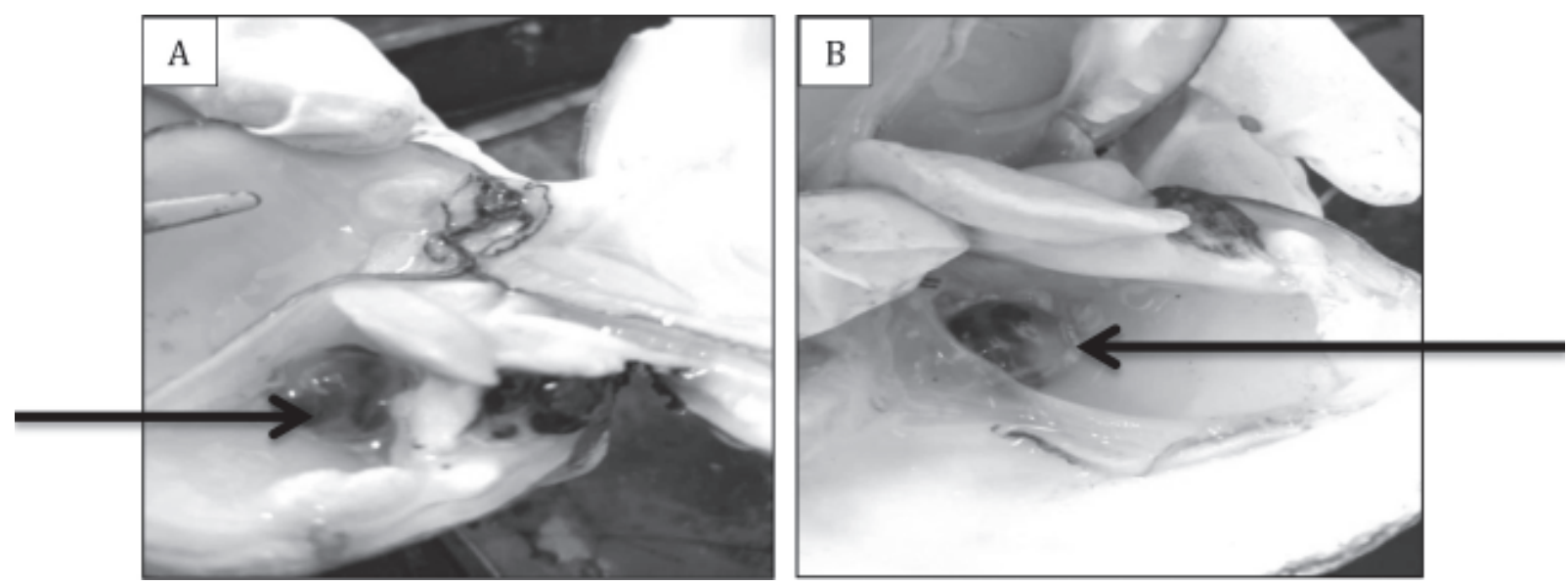

Fig. 5. Showed pea crab (an arrow) was found as in A and B inside the mud clam in the gills area.
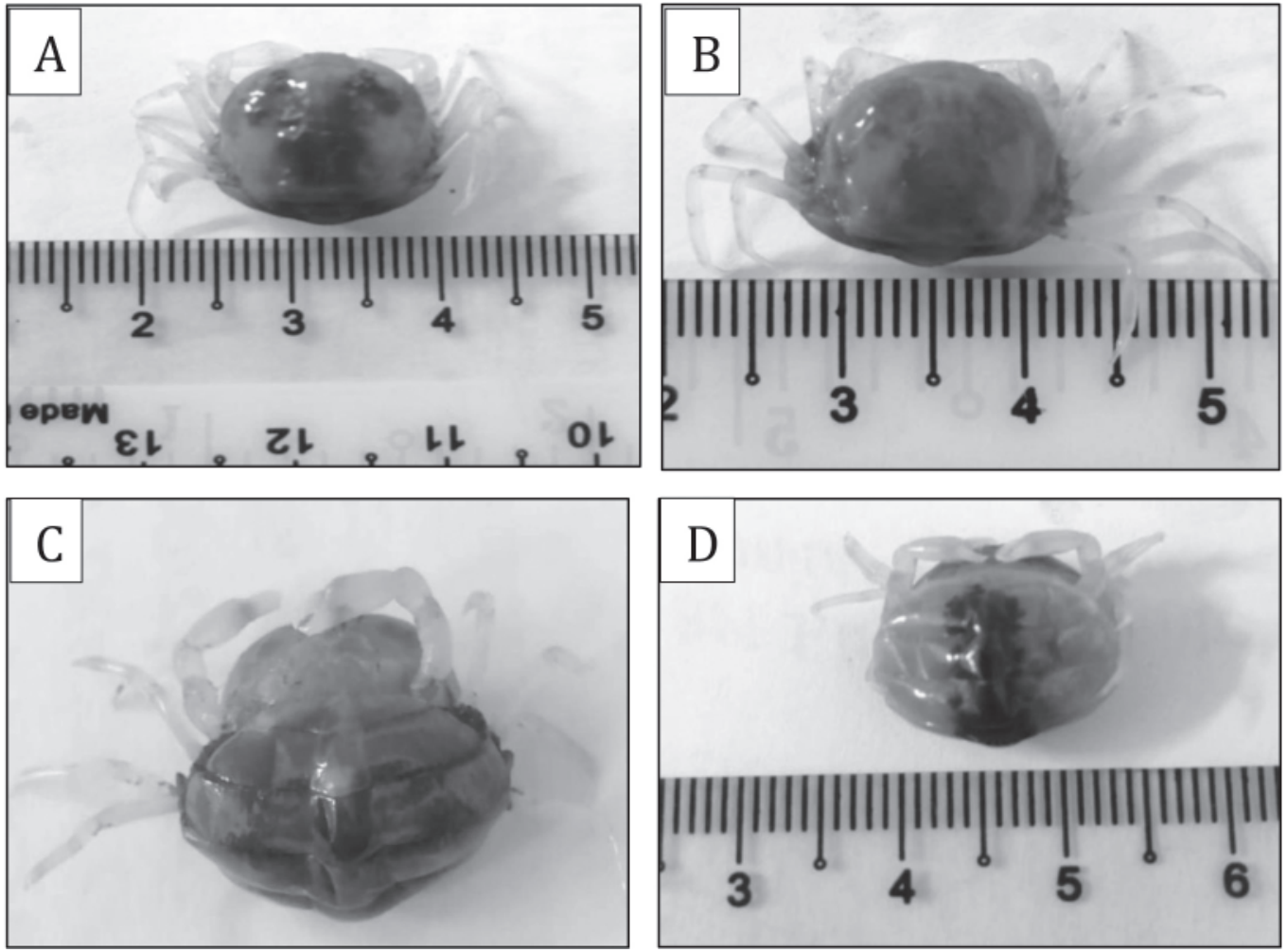

Fig. 6. Arcotheres sp. (A \& B) from dorsal view surface of carapace; (C) Ventral view of female pea crab that filled with egg mass; (D) Ventral view of male pea crab.

Pea crab was furthered examined for its walking morphology. Figure 7 shows the morphology of pea crab-walking legs under a microscopic view. It showed that the third and fourth walking legs of pea crab were longer than the first and the second. Furthermore, the walking legs of the pea crab came with no hairy-like structure. Figure 7(B) showed the cheliped of pea crab and recorded as short setae dense. Whilst, Figure 7(C) showed pea crab's eggs and it was confirmed that the reproductive organ of female pea crab comes with inner brown colour.

\section{DISCUSSION}

Sampling was conducted twice for this study; in October 2018 (first sampling) and February 2019 (second sampling) or on the other hand, monsoon season in October and dry season in February. Rainfall was one of the factors that can affect the distribution of marine animals including pea crab. In the rainy season, the substances in the air, toxic gases, and chemical dissolve are entrapped together. Due to this, the habitat likes mangroves, seagrass, 

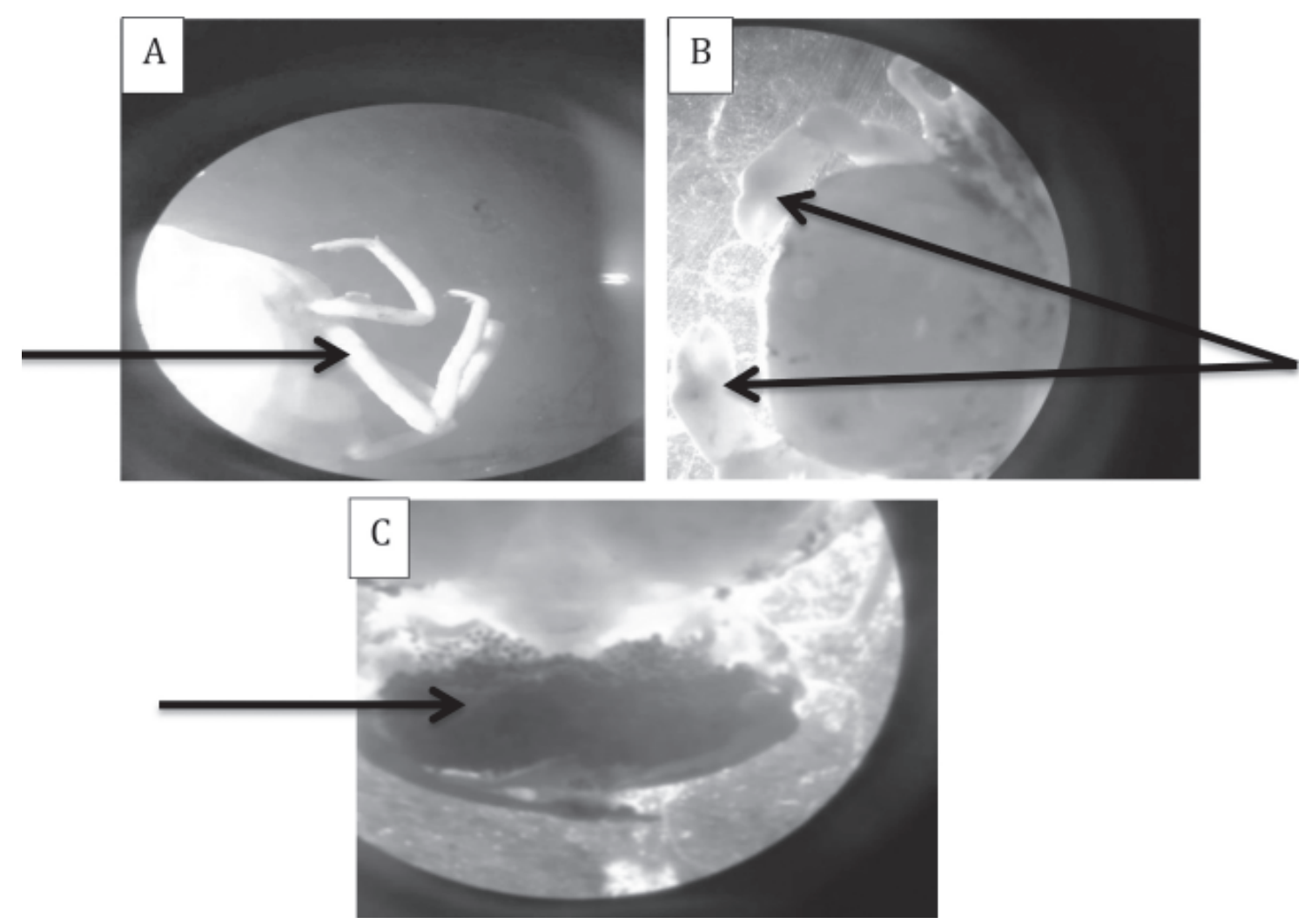

Fig. 7. Arcotheres sp. (A) Structure of walking leg of pea crab (an arrow); (B) Structure of cheliped of pea crab (an arrow); (C) Structure of female pea crab's eggs (an arrow).

salt marshes can be contaminated especially during the freshwater enter the sea. It can cause the turbid water to be thicker with sediment during the monsoon season. So, decreasing in distribution was because of some of the physical-chemical parameters (Varadhajan et al., 2013). Therefore, the number of pea crab isolated also recorded as 15 and 13 respectively in monsoon and dry season (Tables 1 \& 2). As stated by Rosenzweig et al. (2008), climate change was one of the factors that can contribute to the distribution of crab and the pattern of crustacean life was related to environmental factors (Macpherson et al., 2002; Hiddink \& Ter Hofstede, 2008).

Besides, pea crab was one of the examples of crustacean that easily affected to pollution. Therefore, the distribution of crustacean species can be influenced by the physicochemical parameters (Sindermann et al., 1979). The examples of physicochemical parameters that can influence the crustacean species were temperature, salinity, and $\mathrm{pH}$. For the temperature, the changes in the temperature were influenced by tides during monsoon season. Changes in the temperature can affect crustacean's metabolic activities, reproduction, survival, and distribution include migratory behaviours (Le Moullac et al., 2000).
Other than that, $\mathrm{pH}$ also an important factor that can affect the distribution in an ecosystem and the diversity of marine organism. The number of crab species associated with the alkaline $\mathrm{pH}$ was increasing, whereas higher $\mathrm{pH}$ contributed to the decreasing number of crab species (Das et al., 1997) and this can be confirmed by pea crab number isolated during dry season lesser than in monsoon season.

A study reported by Van Hon and Tolley (2009) stated that seasonal rains contributed to the decreasing of salinity during the wet season and hypersaline conditions during the dry season. Thus, the crustacean has endured some dilution of haemolymph at low salinities when there was a rapid change in salinity.

The relationship between the size of the pea crab and its host was demonstrated in Figures 3 and 4 whereas the mud clam length $(\mathrm{mm})$ against pea crab carapace width were plotted. As mentioned in the result, the crab size indicated that the maximum width of the carapace is dependent on the size of the host (Houghton et al., 1963). A study by Kane and Farley (2006), stated that female pea crab that found life in the larger host (pen shells) were significantly larger than female pea crab that lives in scallops. Hence, the larger bivalves were hosted 
larger pea crab than the smaller pea crab. So, it is shown that the larger the host, the larger the size of the pea crab found in it.

Pinnotheridae family was a diverse family that comes as commensalism or parasitic to bivalves. In this study, the identification of genus was determined by macroscopic and microscopic methods. Based on Figures 6 and 7, the genus of the isolated pea crab from this study was identified as Arcotheres (Ikhwanuddin et al., 2019) in which previously reported in Singapore ( $\mathrm{Ng}$ et al., 2018). The carapace of this genus was broader than long, having blunt and have thick lateral margin along interior half. Chelipeds of pea crab came in short setae dense and longer (Qudussi et al., 2016). The female pea crab has smooth and translucent dorsal carapaces. The reproductive organ of female pea crab was visible that comes with inner brown colour (Figure 7C). The colour of the female pea crab came in pale yellow to orange. Meanwhile, the male pea crab possessed yellowish-brown colour and have hard and circular carapace. Moreover, the genus of pea crabs was identified as Arcotheres sp. because of the subhexagonal carapace, the third pair of walking legs remained longer than other pairs of the leg. Besides that, the third and fourth of dactylic walking legs were longer than the first and second walking legs (Pati et al., 2014).

The total number of pea crab isolated from four species of bivalves (oyster, mud clam, cockle, and hard clam) sampled was 15 from first sampling, whilst 13 from second sampling. Thus, it is concluded that seasonal also play a role in this study as more pea crab found during monsoon season and slightly less in the dry season.

From this study, the relationship between the pea crab carapace width $(\mathrm{CW})$ and mud clam shell length (SL) was observed. From the result, it is concluded that larger pea crab was not attracted to the larger host which was mud clam but, in the larger host, there can found smaller pea crab. As it is showed that the size of the pea crab depends on the size of the host. However, further study was needed to explore more about the relationship between the pea crab and the host.

The presence of pea crab in mud clam studied from Setiu Wetlands has been identified as Arcotheres sp. (Ikhwanuddin et al., 2019) and the morphology also was examined.

\section{ACKNOWLEDGEMENTS}

The authors would like to thank the School of Science and Marine Environment, for providing financial support during the sampling, Institute of Aquaculture Tropical, for providing an experimental base and their assistance during identification process of pea crab.

\section{REFERENCES}

Das, J., Das, S.N. \& Sahoo, R.K. 1997. Semidiurnal variation of some physicochemical parameters in the Mahanadi estuary, East coast of India. Indian Journal of Marine Science, 26: 323-326.

Hiddink, J.G. \& Ter Hofstede, R. 2008. Climateinduced increases in species richness of marine fishes. Global Change Biology, 14: 453-460.

Kane, K. \& Farley, G.S. 2006. Body size of the endosymbiotic pea crab Tumidothere maculatus: Larger hosts hold larger crabs. Gulf and Caribbean Research, 18(1): 27-34.

Le Moullac, G. \& Haffner, P. 2000. Environmental factors affecting immune responses in Crustacea. Aquaculture, 191: 21-131.

Macpherson, E. 2002. Large scale species-richness gradients in the Atlantic Ocean. Proceedings of the Royal Society B: Biological Sciences, 269: 1715-1720.

Ng, P.K.L. 2018. Arcotheres placunicola, a new species of pea crab (Crustacea: Brachyura: Pinnotheridae) from the window-pane shell, Placuna ephippium Philipsson, 1788 (Placunidae) in Singapore. Raffles Bulletin of Zoology, 66: 474-485.

Pati, P., Sahu, B.K. \& Panigrahy, R.C. 2014. Pea crab Archotheres alcocki (Rathbun, 1990) as endoparasite of the backwater clam Meretrix casta (Chemnitz, 1782). Indian Journal of Geo-Marine Science, 44(7): 1067-1070.

Qudussi, B.K., Razia, S. \& Farhana, S.G. 2016. Redescription of Arcotheres Placunae and three new records, A.Aff Alcocki, A. Casta and Pinnotheres Quadratus from Pakistan with a note on previously recorded Pakistani pinnotherid crabs. Pakistan Journal of Marine Sciences, 25(1\&2): 131-143.

Rosenzweig, C., Karoly, D., Vicarelli, M., Neofotis, P., Wu, Q., Casassa, G., Menzel, A., Root, T.L., Estrella, N., Seguin, B., Tryjanowski, P., Liu, C., Rawlins, S. \& Imeson, A. 2008. Attributing physical and biological impacts to anthropogenic climate change. Nature, 453: 353-357.

Sindermann, C.J. 1979. Pollution-associated diseases and abnormalities of fish and shellfish: a review. Fish Bulletin, 76: 717-749.

Trottier, O. \& Jeffs, A.G. 2015. Mate locating and access behaviour of the parasitic pea crab, Nepinnotheres novaezelandiae, an important parasite of the mussel Perna canaliculus. Journal of Parasite, 22: 1-11. 
Turra, A., Corte, G.N., Amaral, A.C.Z., Yokoyama, L.Q. \& Denadai, M.R. 2018. Non-linear curve adjustment widen biological interpretation of relative growth analyses of the clam Tivela mactroides (Bivalvia, Veneridae). Peer $J, 6$ : e5070.

Van Hon, J. \& Tolley, S.G. 2009. Acute response of the estuarine crab Eurypanopeus Depressus to salinity and desiccation stress. Journal of Crustacean Biology, 29(4): 556-561.
Varadharajan, D., Soundarapandian, P. \& Pushparajan, N. 2013. Effect of physic-chemical parameters on crabs biodiversity. Journal of Marine Science Research and Development, 3: 116.

Yahya, N.A., Zakaria, N.Z., Taufeq, Z.M., Rosli, N.S. \& Bachok, Z. 2016. Ecology of bivalves in the lagoon area of Setiu Wetlands, Terengganu, Malaysia. Middle-East Journal of Scientific Research, 24(6): 2145-2151. 